\title{
Avaliação Pós-Ocupação do conjunto habitacional Moradias União Ferroviária Bolsão Audi/União, Curitiba (PR)
}

\author{
Post-Occupation Evaluation of the housing estate Moradias \\ União Ferroviária Bolsão Audi/União, Curitiba (PR)
}

\section{Eduardo Francisco Schäfer', Fernanda Paes de Barros Gomide²}

口-

\section{RESUMO}

Este trabalho consiste em uma Avaliação Pós-Ocupação (APO) do conjunto habitacional Moradias União Ferroviária, participante do Sistema Nacional de Habitação de Interesse Social (SNHIS), que promove habitações com qualidade para a população de baixa renda por meio da retirada das famílias de áreas de risco e de insalubridade, fornecendo a elas acesso a todos os equipamentos urbanos necessários. De acordo com a metodologia APO, foram analisados os serviços de esgotamento sanitário, abastecimento de água, drenagem pluvial e coleta de resíduos e a situação de risco quanto a inundações. Assim, por intermédio de avaliações técnicas e comportamentais, buscou-se reconhecer os pontos positivos e negativos do ambiente construído.

Palavras-chave: avaliação pós-ocupação; habitação; salubridade.

\begin{abstract}
This work consists of a Post-Occupation Evaluation (POE) of the housing estate Moradias União Ferroviária, participant of the National System of Housing Social Interest (SNHIS), which promotes quality dwellings for the population of low income, removing families from hazardous and insalubrious areas and providing them with access to all necessary urban equipment. Services of sewage systems, water supply, pluvial drainage and waste collection and the situation of risk regarding floods have been analyzed according to the POE methodology. Therefore, it has been possible to recognize positives and negatives points of the built environment through technical and behavioral assessments.
\end{abstract}

Keywords: post-occupation evaluation; housing; salubrity.

\section{INTRODUÇÃO}

Os conjuntos habitacionais de interesse social têm como objetivo retirar famílias de áreas consideradas de risco e insalubres, fornecendo-lhes uma habitação digna. Dessa maneira, pretendem dar a essas famílias condições ambientais de qualidade, melhorando seus hábitos de viver em comunidade e exercendo seus direitos (ROMÉRO \& VIANA, 2002).

A metodologia de Avaliação Pós-Ocupação (APO) pretende, a partir da avaliação de diversos fatores técnicos, funcionais, econômicos, estéticos e comportamentais e do ponto de vista de técnicos e usuários, diagnosticar aspectos positivos e negativos na solução implantada em ambientes construídos (ORNSTEIN, 1992).

O conjunto habitacional Moradias União Ferroviária (MUF), ambiente escolhido para o estudo, está localizado no bairro do Uberaba, em Curitiba
(PR), inserido no chamado Bolsão Audi/União, que se encontra entre a rodovia BR 277 e a Avenida das Torres, contornado pelo rio Iguaçu e pela linha ferroviária. O bolsão é um aglomerado de vilas irregulares que concentram 3,1 mil casas. As intervenções na área começaram em 2000, com projetos de longo prazo como toda transformação urbana (FAS, 2010).

O objetivo deste estudo de caso foi analisar a situação da pós-ocupação do conjunto habitacional MUF, verificando se a proposta de promover salubridade para essa população e retirá-la de áreas consideradas de risco está sendo atendida.

\section{Avaliação pós-ocupação}

A APO é apresentada como um conjunto de métodos e técnicas de avaliação de desempenho, aplicado a qualquer tipo de ambiente construído

Engenheiro Ambiental da Universidade Tuiuti do Paraná (UTP) - Curitiba (PR), Brasil. 
(por exemplo: empreendimentos habitacionais, escolas, hospitais e parques), visando medir e diagnosticar, levando em conta os especialistas e os níveis de satisfação dos usuários desses ambientes. Assim, são demonstrados os erros e os acertos do ambiente construído, alimentando intervenções, melhorias e programas de manutenção e também realimentando diretrizes para futuros projetos (ROMÉRO \& ORNSTEIN, 2003). Segundo Ornstein (1992), essa metodologia se difere das demais por considerar questões relativas ao projeto e à construção, além de priorizar aspectos de uso, operação e manutenção, essencialmente do ponto de vista do usuário.

A partir de fatores técnicos, funcionais, econômicos e comportamentais, a APO pretende diagnosticar os aspectos positivos e negativos do ambiente construído. No caso do diagnóstico de fatores positivos, estes devem ser cadastrados e recomendados para futuros projetos semelhantes. No caso dos fatores negativos, recomenda-se:

- Minimizar ou mesmo corrigir os problemas detectados por meio de programas de conscientização e de manutenção dos usuários, visando à conservação do ambiente;

- Utilizar os resultados do estudo para otimizar o desenvolvimento de futuros projetos semelhantes (ORNSTEIN,1992).

\section{Assentamentos informais}

Os assentamentos informais são definidos como aglomerações habitacionais de baixa renda, em condição fundiária irregular, invasões de terras e moradias com carência de infraestrutura, podendo estar situados em terrenos públicos ou privados (ABIKO \& COELHO, 2009). Também são mencionados pelo termo favela, que, embora seja alvo de críticas e rejeição por muitas prefeituras e usuários de informações, é a palavra utilizada por prefeituras, pela ONU, em trabalhos científicos e pela população em geral (COSTA \& NASCIMENTO, 2005).

A caracterização de uma favela traz aspectos como situações de insalubridade, riscos estruturais, geológicos e de inundação, além de indicadores desfavoráveis associados à vulnerabilidade social, cujos exemplos são saúde, educação, violência, trabalho e renda. Consequentemente, a mídia a apresenta como um lugar somente habitado por traficantes e outros marginais, mendigos e desocupados. Porém, nem sempre essa situação corresponde à realidade, visto que a maioria dos seus moradores se constitui de trabalhadores, inseridos tanto no mercado formal quanto informal (ABIKO \& COELHO, 2009).

\section{Habitação de interesse social}

A solução de moradia voltada à população de baixa renda é definida no Brasil pelo termo Habitação de Interesse Social (HIS), que vem sendo usado nos estudos sobre gestão habitacional e por várias instituições e agências (ABIKO, 1995).

A conceituação de HIS é muito complexa e amplamente discutida entre os autores da área. Segundo Denaldi (2003), o termo apresenta uma série de variáveis como fatores sociais, econômicos e ambientais e é garantido constitucionalmente como um direito e condição de cidadania. Larcher (2005) conclui os seguintes requisitos básicos que caracterizam a HIS: é financiada pelo poder público, mas não necessariamente produzida pelos governos, podendo a sua produção ser assumida por empresas, associações e outras formas instituídas de atendimento à moradia; é destinada sobretudo a faixas de baixa renda que são objeto de ações inclusivas, notadamente as faixas até três salários-mínimos; e embora o interesse social da habitação se manifeste especialmente em relação ao aspecto de inclusão das populações de menor renda, pode também manifestar-se em relação a outros aspectos como situações de risco, preservação ambiental ou cultural.

No Brasil, foi instituído, pela Lei Federal no 11.124 de 16 de junho de 2005, o Sistema Nacional de Habitação de Interesse Social (SNHIS), que tem como objetivo principal implementar políticas e programas que promovam o acesso à moradia digna para a população de baixa renda. O sistema centraliza todos os programas e projetos destinados à habitação de interesse social e funciona como instrumento de organização dos agentes que atuam na área de habitação e como meio para reunir os esforços das três escalas de governo (União, Estados e municípios) (DENALDI; LEITÃO; AKAISHI, 2011).

Para aderir ao SNHIS, é dever dos Estados, municípios e Distrito Federal constituir um fundo de habitação de interesse social - gerido por conselho gestor com representação dos segmentos sociais ligados à área de habitação - e elaborar um plano de habitação de interesse social em sua esfera de gestão. A adesão ao SNHIS é condição indispensável para que Estados e Municípios obtenham acesso aos recursos do FNHIS (DENALDI; LEITÃO; AKAISHI, 2011).

Os Estados e municípios, ao aderirem ao SNHIS, segundo a lei, comprometem-se a elaborar seus respectivos Planos Locais de Habitação de Interesse Social (PLHIS), que constituem um conjunto articulado de diretrizes, objetivos, metas, ações e indicadores que caracterizam os instrumentos de planejamento e gestão habitacionais nos municípios e Estados, sendo uma condição para poderem ter acesso aos recursos do Fundo Nacional de Habitação de Interesse Social - FNHIS (MINISTÉRIO DAS CIDADES, 2011).

Em Curitiba, no início da década de 1980, a política habitacional do Município propunha não mais a remoção de todas as favelas, e sim colocava em pauta a questão da urbanização em locais onde as condições de salubridade fossem favoráveis e o preço da terra fosse viável. Foi então criado, em 1990, o Fundo Municipal de Habitação. O objetivo desse fundo é dar suporte financeiro aos programas habitacionais de interesse social nos municípios da Região Metropolitana de Curitiba. A maior fonte de arrecadação do Fundo Municipal de Habitação de Interesse Social (FMHIS) — com este nome desde 2007 cujos recursos são geridos pela Companhia de Habitação Popular de Curitiba (COHAB-CT), tem sido proveniente da "compra" de potencial 
construtivo (MILANO \& BONADIO, 2012). Ainda no Plano Diretor de Curitiba de 2004, o capílulo V, referente à Habitação, destaca que as diretrizes gerais da política municipal de habitação estão voltadas para a habitação de interesse social, ou seja, para a população de menor renda (CURITIBA, 2004).

\section{Sustentabilidade da solução}

Em áreas onde são executadas intervenções habitacionais, são necessárias medidas para que a solução seja sustentável — segundo a secretária Nacional de Habitação do Ministério das Cidades, em 2011, Inês Magalhães. "A sustentabilidade de uma intervenção está relacionada com a capacidade de quem conduz o trabalho social na comunidade ser capaz de inserir outros atores municipais e estaduais". A secretária complementa que, tratando-se de conjuntos habitacionais, no trabalho de pós-ocupação, a comunidade precisa continuar sendo objeto de ações articuladas para garantir a sustentabilidade a longo prazo. É também necessário articular políticas que estão disponíveis no Município, nos governos estadual e federal para tornar aquela comunidade mais forte e melhorar a potencialidade daquelas famílias (MINISTÉRIO DAS CIDADES et al., 2011).

Assim, são criados os conjuntos habitacionais de interesse social, devendo oferecer moradias dignas e mais qualidade de vida. Porém, há a necessidade de se avaliar a situação desses conjuntos habitacionais na realidade atual como seu impacto em termos de habitação social e a satisfação de seus usuários. Entendendo assim, o ato de morar exige um esforço em termos de educação social e ambiental, com mudanças de comportamento visando a uma comunidade em que cada membro usufrua as vantagens oferecidas em seu conjunto habitacional, com cada um contribuindo para a manutenção dessas qualidades ambientais (ROMÉRO \& VIANA, 2002).

Segundo Ministério das Cidades et al. (2011), a Secretaria de Meio Ambiente de Curitiba (PR) (SMMA) é um exemplo de sustentabilidade ambiental. A SMMA realiza em parceria com a Companhia de Habitação Popular de Curitiba (COHAB-CT) um trabalho de educação ambiental com diversas ações socioambientais, como as relacionadas aos resíduos e à recuperação de rios. Para isso, nas áreas onde se realizam as realocações, são contratados técnicos de meio ambiente para a orientação educativa às famílias sobre as questões ambientais antes, durante e depois do processo da mudança, tendo como objetivo incorporar essas orientações à cultura dos moradores.

\section{Legislação}

Na cidade de Curitiba (PR), no dia 3 de janeiro de 2000, foi instituída a lei municipal $n^{\circ} 9.800$, que dispõe sobre a divisão do território em zonas e setores e estabelece critérios e parâmetros de uso e ocupação do solo, com o objetivo de orientar e ordenar o crescimento da cidade. Para as áreas de interesse social, a lei estabelece o Setor Especial de
Habitação de Interesse Social (SEHIS), que compreende as áreas onde há interesse público em ordenar a ocupação por meio de urbanização e regularização fundiária, como implantar programas habitacionais de interesse social, sujeitos a critérios especiais de parcelamento, uso e ocupação do solo. Além dessas divisões do território a lei, no $₫ 3^{\circ}$ do Art. 15 , institui que, por proposta do Instituto de Pesquisa e Planejamento Urbano de Curitiba (IPPUC) ao Poder Executivo Municipal, poderão ser criados novos setores especiais, desde que haja interesse público (CURITIBA, 2000c).

Com isso, foi instituído o Decreto ${ }^{\circ} 250 / 2000$, que dispõe sobre a criação de novos setores especiais de habitação de interesse social, declarando como SEHIS as áreas destinadas à implantação, pela COHAB-CT, de novos núcleos habitacionais de interesse social que poderão ser constituídos de lotes, habitações unifamiliares, habitações coletivas, ou mais de uma dessas modalidades indicadas (CURITIBA, 2000b).

As novas criações de SEHIS incluem áreas de proteção ambiental (APA) de interesse social, onde é necessária a intervenção para a urbanização desses locais. Um dos casos é a APA do Iguaçu, onde se concentram alguns núcleos de ocupação irregular, sendo assim, foi estabelecido o Decreto $\mathrm{n}^{\circ} 192$ de 2000, que regulamenta parcialmente o Art. $5^{\circ}$, inciso IX, da lei $n^{\circ} 9.800$, que diz respeito a Área de Proteção Ambiental do Iguaçu, dividindo a APA em áreas de proteção permanente (APP) e setores de uso (CURITIBA, 2000a).

A fim de se proporcionar uma situação de salubridade aos conjuntos habitacionais, torna-se também necessária a instalação de serviços de saneamento básico, que, conforme a Lei Federal $n^{\circ}$ 11.445, que estabelece suas diretrizes, é definido como o conjunto de serviços, infraestruturas e instalações operacionais de abastecimento de água potável, esgotamento sanitário, limpeza urbana e manejo de resíduos sólidos e a drenagem e o manejo das águas pluviais urbanas (BRASIL, 2007).

\section{METODOLOGIA}

Para elaboração da pesquisa, foram feitas revisões bibliográficas de publicações, livros e artigos; análise técnica em campo por meio de visitas técnicas ao conjunto habitacional; aquisição de dados com os órgãos responsáveis por estudos e desenvolvimento de projetos para habitação de interesse social; além de questionários com a população da área em estudo e relatório fotográfico.

\section{Avaliação Pós-Ocupação}

A metodologia utilizada na avaliação do conjunto habitacional MUF é a APO, que pretende, a partir da avaliação de fatores técnicos, funcionais e comportamentais, diagnosticar aspectos positivos e negativos do ambiente construído. 
Em uma pesquisa de APO, pode-se dividir a avaliação em três níveis:

1. APO indicativa ou de curto prazo: por entrevistas com usuários-chave, indica os principais aspectos positivos e negativos do ambiente;

2. APO investigativa ou de médio prazo: além dos pontos positivos e negativos, traz a explicitação de critérios referenciais de desempenho;

3. APO diagnóstico ou de longo prazo: são detalhados os critérios de desempenho, utilizando-se de técnicas mais sofisticadas de medidas, de modo que sejam correlacionadas as mudanças físicas no ambiente com as respostas dos usuários (ORNSTEIN, 1992).

O nível de avaliação desta pesquisa é a APO indicativa ou de curto prazo, por meio de avaliações técnicas e comportamentais.

\section{Avaliação técnica}

Por intermédio da avaliação técnica, procurou-se verificar os seguintes objetivos utilizando a Lei Federal n ${ }^{\circ}$ 11.455/2007 como referência:

- Avaliar o abastecimento de água;

- Avaliar a rede de esgoto;

- Avaliar o sistema de drenagem pluvial;

- Avaliar o sistema de acondicionamento e coleta de resíduos;
- Avaliar se a população está ou não em área considerada de risco de inundação.

Essa etapa foi realizada por entrevistas com técnicos da COHAB-CT e Companhia de Saneamento do Paraná (SANEPAR), além de visitas técnicas e relatórios fotográficos.

\section{Avaliação comportamental}

Para conhecer e verificar a situação de salubridade das famílias do conjunto habitacional, foi necessária a avaliação comportamental, por meio da aplicação de questionários com os usuários do ambiente, as entrevistas com pessoas-chave da área e a seleção amostral dos resultados.

Com a utilização da Avaliação Técnica e a Avaliação Comportamental para a verificação dos objetivos, a APO foi estruturada conforme mostra a Figura 1.

\section{Elaboração do questionário}

Conforme Gil (1996), os questionários consistem em traduzir os objetivos propostos na APO, definidas algumas regras na sua elaboração como: as questões devem ser fechadas, com respostas simples de fácil entendimento, devem ser apenas relacionadas ao estudo, não devem penetrar na intimidade das pessoas, devem possibilitar única interpretação e devem ser feitas de maneira clara e objetiva.

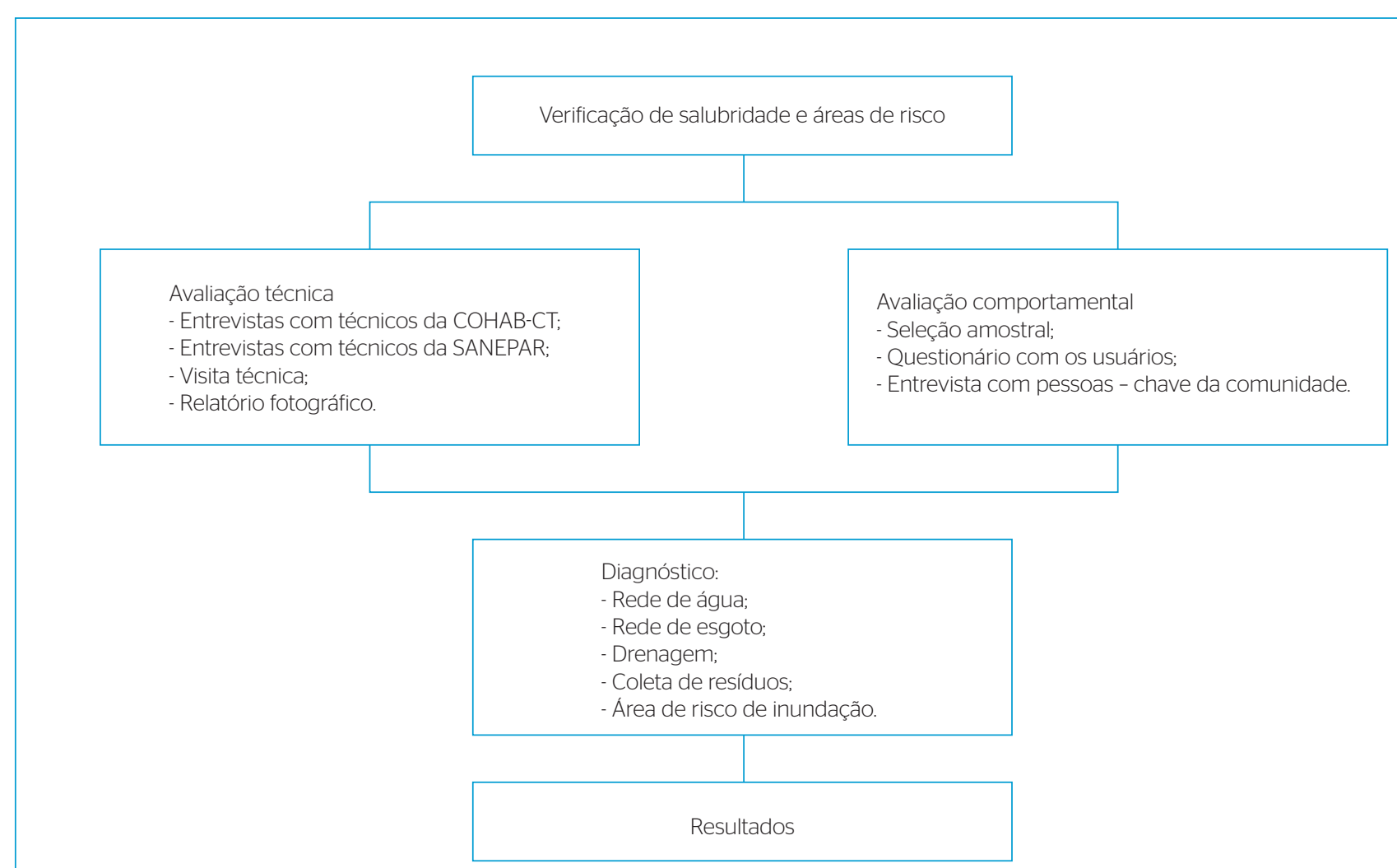

Figura 1 - Estrutura de Avaliação Pós-Ocupação. 
Segundo a metodologia, para que os dados obtidos tenham relevância e para que demonstrem a realidade, utilizando-se de um nível de confiança de $90 \%$, a quantidade de questionários é calculada conforme o tamanho da população e a margem de erro que se quer obter, conforme Tabela 1 (GIL, 1996).

No conjunto habitacional MUF, onde atualmente residem 214 famílias, totaliza-se aproximadamente uma população de 1.000 moradores, de acordo com a assistente social Danniele Gatto, da COHAB-CT. Para essa população, tem-se uma amostra de 91, conforme Gil (1996). O questionário a seguir (Quadro 1) foi elaborado para a avaliação comportamental dentro da APO, levando em consideração que todas as perguntas foram respondidas por pessoas com idade acima de 16 anos. Dentro do conjunto habitacional, foram 91 questionários aplicados aleatoriamente, com perguntas sobre o conhecimento dos usuários a respeito do sistema de saneamento e como eles qualificam esses equipamentos urbanos, aos quais muitos moradores não tinham acesso antes do reassentamento.

\section{RESULTADOS}

O ambiente estudado é o conjunto habitacional MUF, localizado dentro do chamado Bolsão Audi/União, que se encontra no bairro Uberaba, na cidade de Curitiba (PR), entre a rodovia BR-277 e a Avenida das Torres, contornada pelo rio Iguaçu e pela linha ferroviária (Figura 2). O bolsão é um aglomerado de vilas irregulares que concentra 3,1 mil casas (FAS, 2010).

Conforme dados da COHAB-CT, o total de moradias no projeto é 473 - 250 casas já foram construídas, e, segundo o arquiteto Valter Rebelo, da Coordenadoria de Projeto Especiais, e a assistente social Danniele Gatto, ambos da COHAB-CT, dessas 250 moradias, 214 estão ocupadas, totalizando aproximadamente 1.000 moradores. A ocupação do MUF teve início em agosto de 2009 e tem previsão de término para julho de 2015. As famílias que estão residindo nessas casas são oriundas de áreas próximas ao conjunto, como Vila Icaraí, Vila Audi, Jardim União, Vila União Ferroviária e Alvorada, algumas delas reassentadas devido às obras de urbanização.

Uma das intervenções na região foi resolver o problema dos alagamentos, e, segundo o engenheiro civil Edymilson Luiz dos Santos, do Departamento de Engenharia da COHAB-CT, foi adotada uma solução que consiste em um sistema de contenção de cheias com a utilização de diques, um canal que acompanha o rio Iguaçu e uma lagoa de acumulação, solução implantada junto com a Secretaria Municipal de Obras Públicas (SMOP).

$\mathrm{Na}$ estruturação da área, também foi organizado o sistema viário local, com a criação de rua estruturante, paralela a um dos diques, que isola a faixa de preservação permanente do rio Iguaçu e impede nova ocupação indevida do local. Além disso, as ruas

Tabela 1 - Tamanho da amostra e precisão de estimativas da população.

\begin{tabular}{l|c|c|c}
\multirow{2}{*}{ Tamanho da população } & \multicolumn{3}{|c}{ Margem de erro } \\
\cline { 2 - 4 } & $\pm 3 \%$ & $\pm 5 \%$ & $\pm 10 \%$ \\
\hline 1.000 & - & 286 & 91 \\
\hline 2.000 & 714 & 333 & 95 \\
\hline 5.000 & 909 & 370 & 98 \\
\hline 10.000 & 1.000 & 383 & 99 \\
\hline
\end{tabular}

Quadro 1 - Questionário.

\begin{tabular}{|c|c|}
\hline O1. Há quanto tempo mora nesta residência? & \\
\hline & $\square \operatorname{Sim}$ \\
\hline 2. Ientilagua encanlada! & $\square$ Não \\
\hline & $\square \operatorname{Sim}$ \\
\hline & $\square$ Não \\
\hline & $\square \operatorname{Sim}$ \\
\hline & $\square$ Não \\
\hline & $\square \mathrm{Sim}$ \\
\hline Us. Descae que moram aqul, houve algum caso de alarreld! & $\square$ Não \\
\hline & $\square \operatorname{Sim}$ \\
\hline 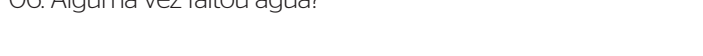 & $\square$ Não \\
\hline & $\square \operatorname{Sim}$ \\
\hline \%. Iem instalaçao ae esgoto? & $\square$ Não \\
\hline O8. Algum dia sentiu algum cheiro forte vindo do ralo do & $\square \mathrm{Sim}$ \\
\hline banheiro? & $\square$ Não \\
\hline & $\square \operatorname{Sim}$ \\
\hline 09. Houve algum problema com entupımento ou vazamento? & $\square$ Não \\
\hline & $\square \mathrm{Sim}$ \\
\hline Tu. Ma coleta ne MxU? & $\square$ Não \\
\hline & $\square \operatorname{Sim}$ \\
\hline 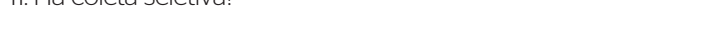 & $\square$ Não \\
\hline 12. Houve acúmulo de água durante as chuvas na sua proprie- & $\square \mathrm{Sim}$ \\
\hline dade? & $\square$ Não \\
\hline 13. Houve acúmulo de água durante as chuvas nas ruas do & $\square \mathrm{Sim}$ \\
\hline conjunto? & $\square$ Não \\
\hline & $\square \mathrm{Sim}$ \\
\hline 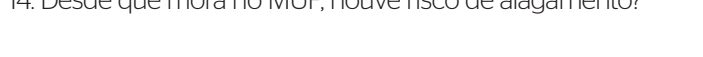 & $\square$ Não \\
\hline
\end{tabular}




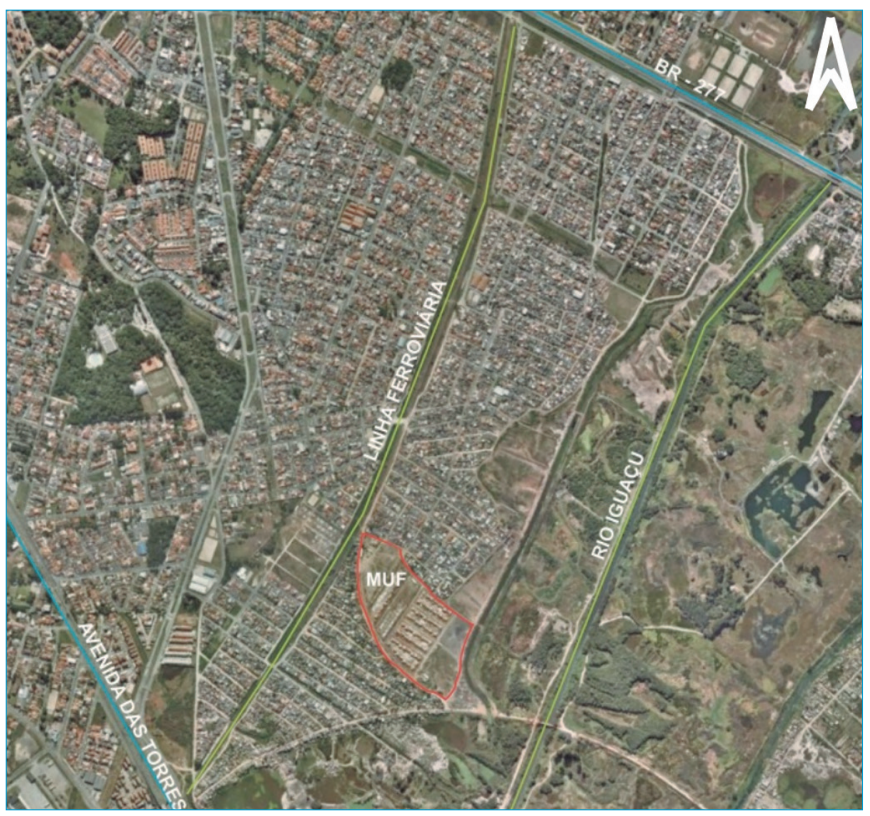

$25^{\circ} 29^{\prime} 42.46^{\prime \prime} \mathrm{S} / 49^{\circ} 12^{\prime} \mathrm{O} 1.4 \mathrm{O}^{\prime \prime} \mathrm{O}$

Fonte: Adaptado do Google Earth

Figura 2 - Localização Moradias União Ferroviária.

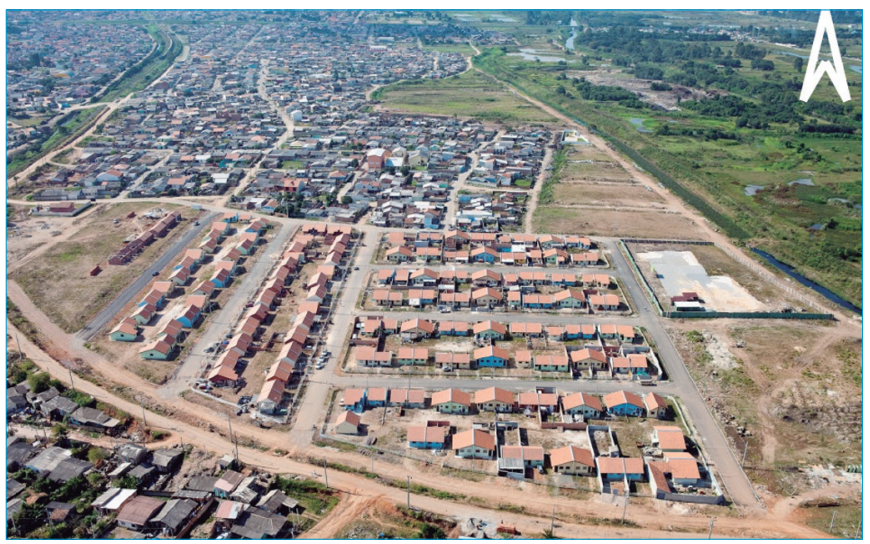

Fonte: $\mathrm{COHAB-CT}$.

Figura 3 - Imagem aérea do Moradias União Ferroviária em 2010.

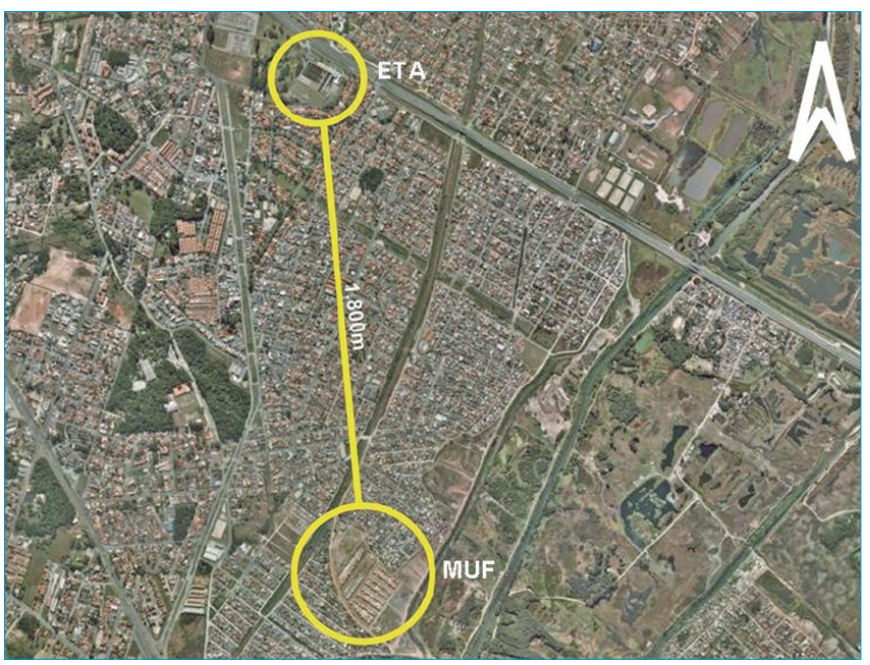

Fonte: Adaptado do Google Earth.

Figura 4 - Localização da Estação de Tratamento de Água Iguaçu. internas estão sendo pavimentadas e as redes de água e energia elétrica instaladas, substituindo as ligações clandestinas existentes (COHAB-CT, 2010).

As obras do conjunto MUF fazem parte do programa Morar em Curitiba. Trata-se de uma ação da prefeitura de Curitiba, com recursos provenientes do PAC/OGU que são o Programa de Aceleração do Crescimento do Governo Federal do Brasil, e o Orçamento Geral da União (ABCONLINE, 2008). Na Figura 3, a imagem aérea do MUF em 2010.

O presente estudo foi organizado verificando-se, a partir de informações técnicas e comportamentais, a situação de salubridade do conjunto habitacional. As entrevistas para avaliação comportamental ocorreram nos dias 9, 11 e 21 de novembro de 2011. Para o início das questões realizadas com os moradores, houve a necessidade de se conhecer há quanto tempo eles estavam residindo no conjunto habitacional, para verificar o tempo de uso daquele ambiente construído. Como resposta, $48 \%$ dos moradores disseram estar morando entre um e dois anos no MUF.

\section{Abastecimento de água}

Conforme visita técnica no local e informações dos engenheiros da SANEPAR Nilton Cezar e Carlos Kosak, todas as residências do conjunto habitacional têm água encanada, aparentemente de boa qualidade, oriundas da Estação de Tratamento de Água (ETA) Iguaçu, localizada a aproximadamente $1.800 \mathrm{~m}$ do MUF, como mostra a Figura 4.

As informações foram confirmadas pela avaliação comportamental, na qual todos os entrevistados responderam ter água encanada, $80 \%$ afirmaram que essa água chega até a residência sem nenhum gosto aparente e $90 \%$, que a água chega de forma transparente. Ainda, 83 dos 91 entrevistados disseram não ter ocorrido nenhum caso de doença por contaminação na água desde que residem no MUF. Porém, 51\% dos moradores entrevistados afirmaram ter faltado água alguma vez na residência, fato que não acarretou descontentamento por estes terem caixas de água para armazenamento e a falta de água não ter se prologado por mais de um turno no dia. A limpeza das caixas de água não foi questionada neste trabalho.

\section{Rede de esgoto}

Em relação ao esgotamento sanitário do conjunto, segundo o engenheiro Carlos Kosak, da SANEPAR, responsável por acompanhar as obras de instalação da rede de esgoto no MUF, todas as casas construídas estão com as ligações devidamente instaladas. Esse fato foi confirmado nas entrevistas com os moradores, já que $97,8 \%$ responderam ter instalação de esgoto na residência, e os demais responderam negativamente por desconhecimento. Além disso, por meio de visita técnica, pôde-se confirmar a instalação da rede dentro do conjunto habitacional. 
Os efluentes vindos do MUF são direcionados para uma Estação Elevatória localizada nas proximidades do conjunto (Figura 5). A responsável pelo projeto da estação, a engenheira Carla Valente Jacomel, da SANEPAR, esclarece que o esgoto está sendo recalcado pela estação elevatória até um coletor existente ligado a ETE Atuba Sul, localizada a $2.800 \mathrm{~m}$ do conjunto habitacional.

Apesar de todas as casas terem tido a rede de esgoto instalada com supervisão dos engenheiros da SANEPAR, 30\% dos moradores entrevistados responderam que tiveram algum tipo de vazamento ou entupimento nas instalações.

\section{Drenagem pluvial}

A partir da visita técnica, verificou-se a existência de um sistema de drenagem pluvial (ou microdrenagem) no conjunto habitacional. Segundo o engenheiro Edymilson Luiz dos Santos, da COHAB-CT, as redes de águas pluviais estão sendo encaminhadas para o canal que acompanha o rio Iguaçu, localizado a aproximadamente $100 \mathrm{~m}$ das moradias, e subsequentemente as águas seguem até uma lagoa de acumulação. Porém, é observada no desemboque da rede pluvial (Figura 6) a falta de manutenção nos coletores.

Apesar de o sistema estar instalado, verificaram-se por meio de visita técnica e relatório fotográfico falhas de manutenção das bocas de lobo. Estas são a entrada da água das chuvas até a rede pluvial, mas encontram-se encobertas com pedra, areia e resíduos (Figura 7). Além disso, conforme a assistente social Danniele Gatto, a varrição das ruas do MUF, uma das alternativas de manutenção, só é realizada quando solicitada ao Departamento de Limpeza Pública, órgão municipal que confirmou a informação.

Em um dia com precipitação, foi possível verificar, em visita ao MUF, que essa falta de manutenção está comprometendo o sistema de microdrenagem do conjunto habitacional (Figura 8). Essa situação foi confirmada, pois $44 \%$ dos moradores entrevistados na avaliação comportamental afirmaram que há acúmulo significativo de água nas ruas do MUF quando chove. Informaram, ainda, que muitas vezes há dificuldades na travessia das ruas devido a esse problema.

Além do acúmulo de água nas ruas, 52\% dos moradores entrevistados responderam ter problemas com a drenagem dentro do seu terreno, principalmente nos fundos da casa. Porém, muitos daqueles que responderam não ter qualquer problema com acúmulo informaram ter aterrado ou impermeabilizado o terreno para acabar com essa situação. No relatório fotográfico (Figura 9), é relatado o problema do acúmulo de água nos lotes.

Ainda, $48 \%$ dos entrevistados informaram que, nos dias de chuva ou até mesmo nos ensolarados, frequentemente é possível sentir fortes odores desagradáveis vindos do ralo do banheiro.

Além do sistema de contenção de enchentes, citado anteriormente, não houve projeto para baixar o lençol freático na área estudada.

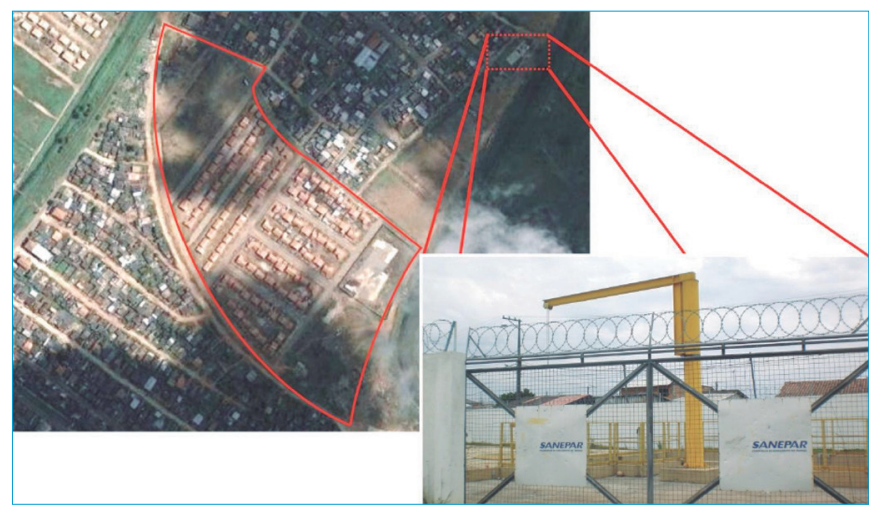

Fonte: Adaptado do Google Earth.

Figura 5 - Estação Elevatória (2011).

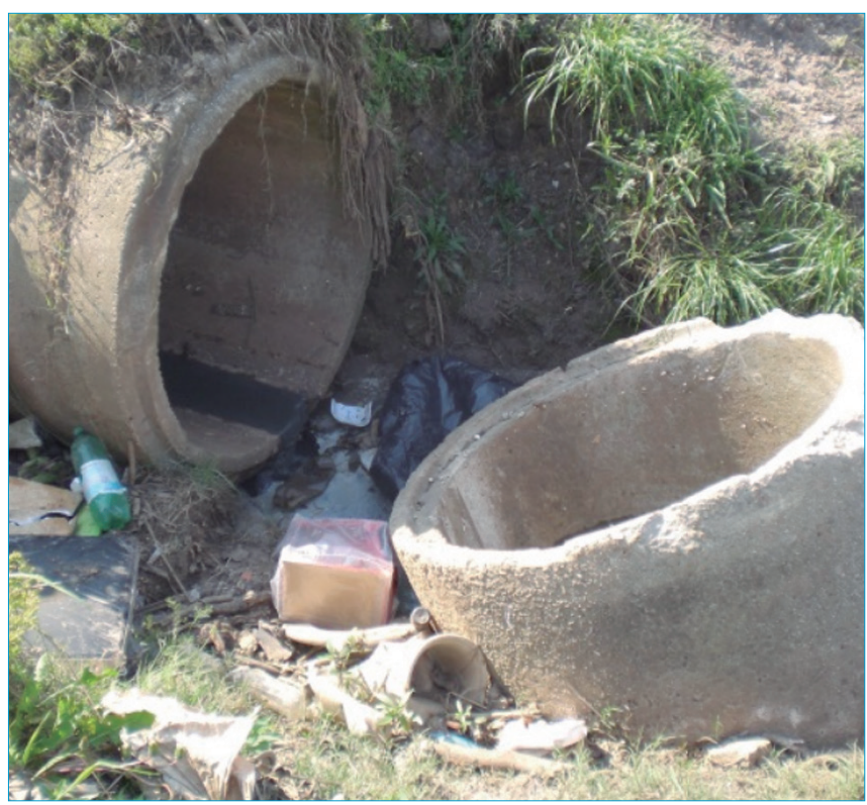

Figura 6 - Desemboque da rede (2011).

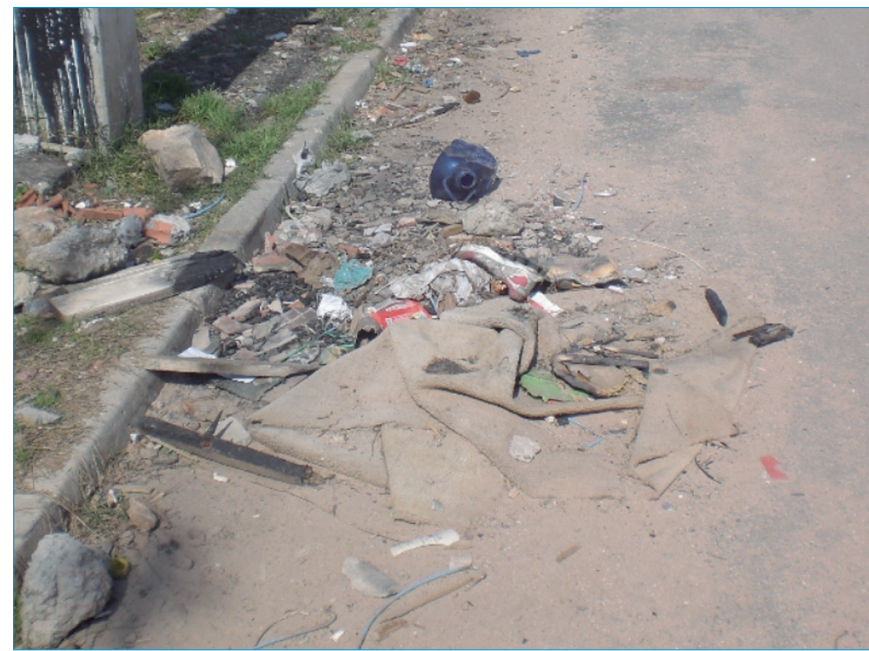

Figura 7 - Boca de lobo encoberta (2011). 


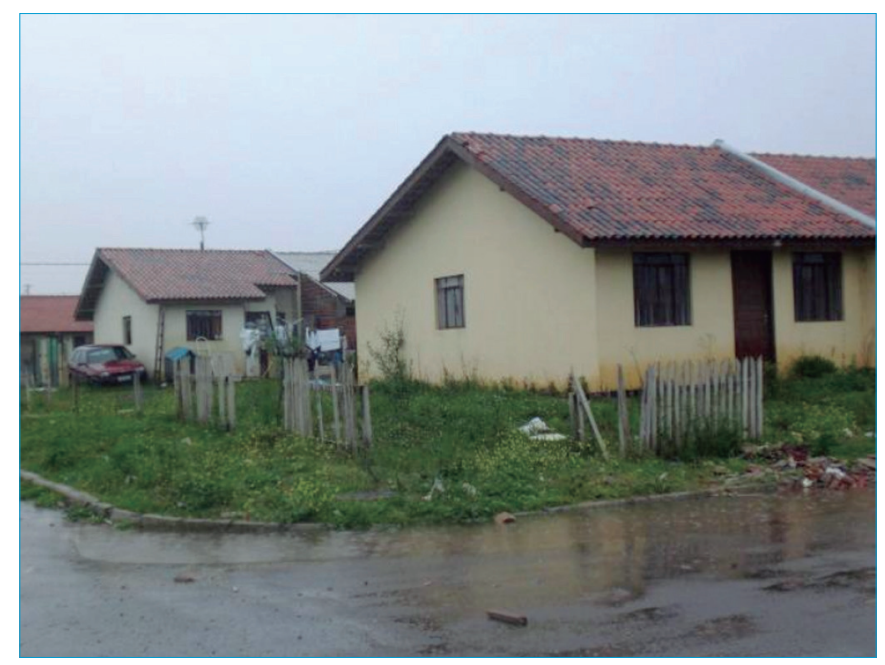

Figura 8 - Acúmulo de água nas ruas (2011).

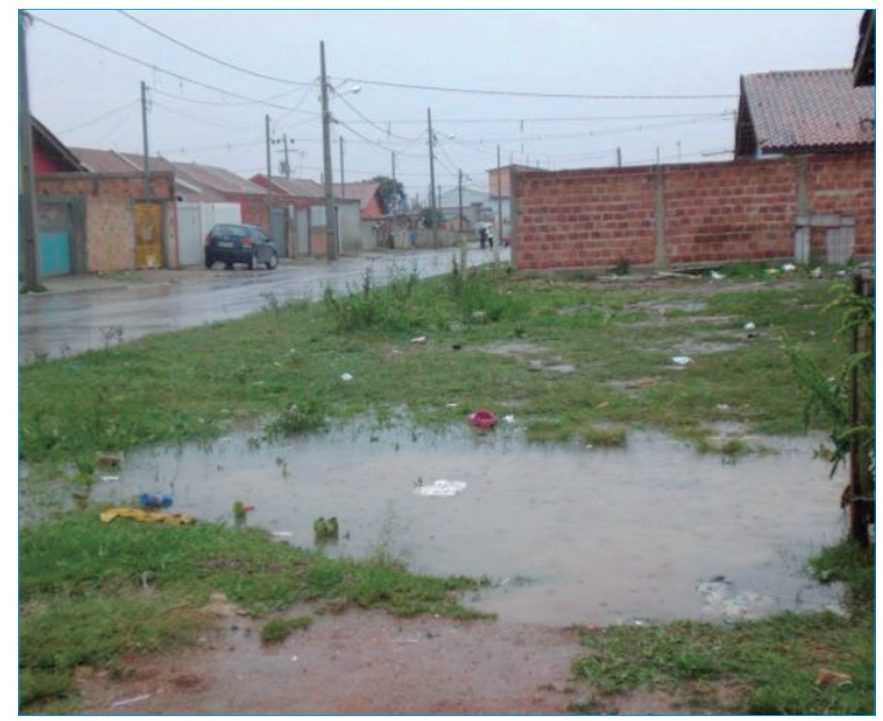

Figura 9 - Acúmulo de água no lote (2011).

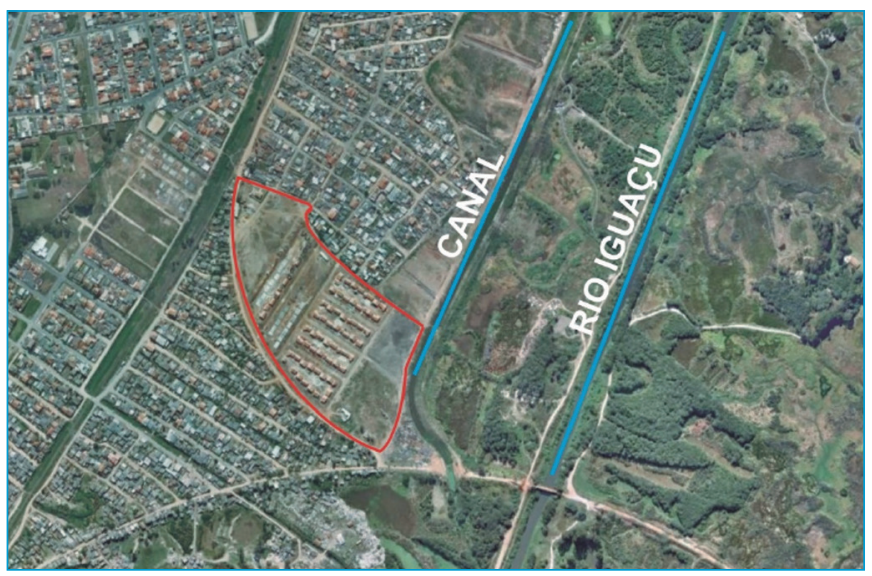

Fonte: Adaptado do Google Earth.

Figura 10 - Canal - Rio Iguaçu.

\section{Acondicionamento e coleta de resíduos}

As moradias do conjunto habitacional têm lixeira para acondicionar o lixo doméstico. De acordo com o técnico de Gestão Pública Gilberto Hanig, do Departamento de Limpeza Pública da Prefeitura de Curitiba, há coleta de lixo orgânico 3 vezes na semana, o que foi confirmado pela avaliação comportamental, na qual 100\% dos entrevistados responderam ter o serviço de coleta de lixo na rua da sua residência.

Além disso, 91\% dos moradores informaram que, uma vez na semana, o caminhão de coleta seletiva passa na sua residência, informação confirmada com o Departamento de Limpeza Pública.

\section{Riscos de inundação}

A área onde se encontra o conjunto habitacional e suas proximidades era uma região com alto risco de inundação. Porém, o arquiteto Valter Rebelo e a assistente social Danniele Gatto, ambos da COHAB-CT, informaram que não houve nenhum registro de inundação desde que o MUF foi criado - consequência da instalação do sistema de contenção de cheias, que inclui 2 diques de 12,0 $\mathrm{m}$ de largura, 1,5 $\mathrm{m}$ de altura e 2,5 km de extensão total (de uma ponta a outra da área do bolsão), e têm, em uma das extremidades, um sistema de bombeamento para controlar o volume de água na área (COHAB-CT, 2010). Pela análise comportamental, foi confirmada a eficiência da solução, pois apenas $4 \%$ dos moradores relataram alguma inundação.

Incluído no sistema de contenção de cheias, foi construído um canal que acompanha o rio Iguaçu (Figura 10), com a função de melhorar o escoamento da água das chuvas além de ser o desemboque da rede de microdrenagem do conjunto habitacional (COHAB-CT, 2010).

\section{DISCUSSÕES}

\section{Abastecimento de água}

De acordo com as avaliações realizadas, o abastecimento de água é considerado um ponto positivo dentro da APO, pois atende todo o conjunto habitacional de maneira eficiente.

Porém, na avaliação comportamental, pontos como gosto e transparência da água foram apontados como negativos, além da falta de água em alguns casos. Entretanto, verificou-se que esses resultados se devem ao período de manutenção do sistema de abastecimento, não sendo indicativos de falha no fornecimento de água. Nos casos mencionados sobre doenças relacionadas com a qualidade da água, estes aconteceram com crianças, o que pode estar relacionado aos problemas na drenagem pluvial do conjunto.

É importante salientar que, se não houver manutenção pelos moradores das caixas de água, futuros problemas poderão surgir quanto à qualidade da água caso as pessoas não sejam informadas e orientadas da necessidade de limpeza. 


\section{Rede de esgoto}

O esgotamento sanitário do MUF é direcionado para uma estação de tratamento, evitando a contaminação do solo e de corpos d'água, uma nova realidade para as famílias que hoje moram nas residências do conjunto habitacional, pois, antes do reassentamento, todo esgoto gerado por elas era direcionado para pequenos riachos (valetas) que passavam próximo as suas moradias e desembocavam no rio Iguaçu.

Entretanto, como mostra a avaliação comportamental, 30\% dos moradores entrevistados tiveram problemas com entupimento ou vazamento na rede de esgoto, demonstrando um ponto negativo na avaliação. Alguns moradores acabaram refazendo erroneamente as instalações da rede sem o consentimento da $\mathrm{COHAB}-\mathrm{CT}$, direcionando as novas tubulações para a rede pluvial, o que acabou afetando significativamente o sistema.

É necessária uma revisão nas dimensões e no tipo de canalização usados na construção da rede para que o problema não ocorra nos novos conjuntos habitacionais.

\section{Drenagem pluvial}

O sistema de drenagem pluvial do MUF é analisado em duas diferentes situações, a primeira trata da drenagem no terreno dos usuários e a segunda, a drenagem nas ruas do conjunto. Nas duas avaliações realizadas, ambas as situações podem ser consideradas negativas.

$\mathrm{Na}$ primeira, o acúmulo de água dentro da propriedade causa desconforto e riscos a seus moradores, pois, segundo relatos, a água acumulada permanece no terreno por alguns dias sem escoar, podendo atrair vetores e colocando os usuários em risco quanto à saúde, não atendendo, assim, a proposta de manter uma situação salubre na área construída.

A outra situação é a drenagem das ruas. O descuido por parte de alguns usuários e a falta de manutenção acabaram obstruindo as bocas de lobo com diversos materiais, dificultando ou mesmo evitando o escoamento das águas pluviais. Outro ponto negativo, como mencionado, são as reinstalações da rede de esgoto direcionadas para as galerias de águas pluviais, contaminando o canal de desemboque, que também é prejudicado pela falta de cuidado e manutenção, como mostrou o relatório fotográfico.

O fator mais preocupante em toda a situação é quando o efluente direcionado para as galerias se mistura com a água pluvial, e, em dias de chuva mais intensa, volta à superfície, colocando em risco todos os usuários do conjunto habitacional. Dessa forma, constatou-se que o risco de ocorrerem doenças de veiculação hídrica não foi solucionado pelo sistema de drenagem pluvial.

\section{Acondicionamento e coleta de resíduos}

Confrontando as avaliações técnicas e comportamentais, foi verificado que o quesito acondicionamento e coleta de resíduos está dentro das conformidades exigidas, estando o ambiente provido de todos os elementos necessários. Dentro da APO, trata-se de um ponto positivo, por haver lixeiras para acondicionamento e coleta de resíduos orgânicos e recicláveis em todo o conjunto habitacional. Vale salientar que muitos moradores do MUF têm como renda familiar a atividade de coleta e venda de resíduos recicláveis, tornando desnecessário esse serviço caso haja um acordo entre a prefeitura e os usuários.

Notou-se a existência de resíduos da construção civil, provenientes das obras de reforma e ampliação, dentro do MUF. Entretanto, esses materiais não têm sido descartados adequadamente.

\section{Riscos de inundação}

O principal problema enfrentado pela população da área do Bolsão Audi/União, antes das intervenções da COHAB-CT, eram as inundações que ocorriam frequentemente quando havia chuvas intensas na região. Agora, com o sistema de contenção de cheias implantado, esse transtorno não incomoda mais os moradores, comprovado pelas avaliações técnicas e comportamentais, sendo que os usuários entrevistados que relataram problemas o confundiram com o acúmulo de água durante as chuvas, ocasionado principalmente pela falta de manutenção do sistema de drenagem pluvial da área do conjunto habitacional.

\section{CONCLUSÕES}

O trabalho verificou que a maior parte da população, que hoje reside nas casas do conjunto habitacional, dispõe de equipamentos urbanos e uma situação considerada salubre e segura. Entretanto, para garantir a eficiência do projeto, é necessária a manutenção do ambiente construído pelos próprios usuários. Enfim, para que haja melhoramento e continuidade do projeto, é essencial a implementação de um trabalho educacional intensivo por todos os envolvidos.

Para a sustentabilidade dessa solução, é de suma importância algumas medidas para controle e manutenção do ambiente construído. Sugere-se:

- A elaboração de políticas sociais e ambientais por parte do município e governos estadual e federal;

- Ações efetivas de educação ambiental dos usuários de curto, médio e longo prazos;

- O acompanhamento dos usuários por profissionais habilitados que conduzam e orientem os trabalhos sociais dentro da comunidade, tornando-as mais fortes e unidas.

Dessa forma, mudanças significativas surgirão no comportamento dos usuários - os principais responsáveis para a manutenção da solução - , fazendo com que cada membro usufrua das vantagens do conjunto habitacional e contribua para a manutenção de suas qualidades ambientais e sociais. 


\section{REFERÊNCIAS}

ABCONLINE - Associação Brasileira de COHAB's e Agentes Públicos de Habitação. (2008) Selo de Mérito - Urbanização e preservação ambiental. Curitiba. Disponível em: <http://www.abconline.org.br/ Downloads/SELO\%20DE\%20M\%C3\%89RITOProjeto\%20COHAB\%20 CT.pdf>. Acesso em: 16 out. 2011.

ABIKO, A.K. (1995) Introdução à gestão habitacional. Texto Técnico da Escola Politécnica da USP, Departamento de Engenharia da Construção Civil, TT/PCC/12. São Paulo: EPUSP.

ABIKO, A.K. \& COELHO, L.O. (2009) Urbanização de favelas: procedimentos de gestão. Série Recomendações Técnicas Habitare - v. 4. Porto Alegre: ANTAC. $88 \mathrm{p}$.

BRASIL. (2007) Lei $\mathrm{n}^{\circ} 11.445$, de 05 de janeiro de 2007. Estabelece diretrizes nacionais para o saneamento básico; altera as Leis nos 6.766, de 19 de dezembro de 1979, 8.036, de 11 de maio de 1990, 8.666, de 21 de junho de 1993, 8.987, de 13 de fevereiro de 1995; revoga a Lei no 6.528, de 11 de maio de 1978; e dá outras providências. Diário Oficial da União, Poder Legislativo, Brasília, DF, 08 jan. 2007, p. 3.

COHAB-CT. (2010) Obras mudam a paisagem da Vila Audi e a vida dos moradores da região. Publicado em 05 nov. 2010. Disponível em: <http://www.cohabct.com.br/conteudo.aspx?conteu do=163>. Acesso em: 15 out. 2011.

COSTA, V.G. \& NASCIMENTO, J.A.S. (2005) O Conceito de Favelas e assemelhados sob olhar do IBGE, das Prefeituras do Brasil e da ONU. In: Encontro de Geógrafos da América Latina, 10, 20 a 26 de março de 2005, São Paulo: Universidade de São Paulo.

CURITIBA (Município). (2000a) Decreto n 192 de 03 de abril de 2000. Regulamenta parcialmente o Art. $5^{\circ}$, inciso IX, da Lei $n^{\circ}$ 9.800/00, no que diz respeito à Área de Proteção Ambiental do Iguaçu, Parque Municipal do Iguaçu e dá outras providências. Palácio 29 de março, Secretaria Municipal de Meio Ambiente, Curitiba, PR, 03 abr. 2000.

CURITIBA (Município). (2000b) Decreto n²50, de 03 de maio de 2000. Dispõe sobre a criação de novos setores especiais de habitação de interesse social. Palácio 29 de Março, Secretaria Municipal de Meio Ambiente, Curitiba, PR, 03 mai. 2000.

CURITIBA (Município). (2000c) Lei n 9.800, 03 de janeiro de 2000. Dispõe sobre o Zoneamento, Uso e Ocupação do Solo no Município de Curitiba e dá outras providências. Câmara Municipal de Curitiba, Curitiba, PR, 03 jan. 2000.

CURITIBA (Município). (2004) Lei no 11.266, 16 de dezembro de 2004. Dispõe sobre a adequação do Plano Diretor de Curitiba ao Estatuto da Cidade - Lei Federal n 10.257/01, para orientação e controle do desenvolvimento integrado do município. Palácio 29 de março, Câmara Municipal de Curitiba, Curitiba, PR, 16 dez. 2004.
DENALDI, R. (2003) Política de urbanização de favelas: evolução e impasses. Tese (Doutorado em Arquitetura e Urbanismo) - Faculdade de Arquitetura e Urbanismo da Universidade de São Paulo, São Paulo. Disponível em: <http://rosanadenaldi.com/PDF/Tese\%20completa. pdf > . Acesso em: 02 ago. 2013.

DENALDI, R.; LEITÃO, K.; AKAISHI, A. (2011) O recente processo de elaboração de Planos Locais de Habitação de Interesse Social no Brasil: limitações e perspectivas. In: Encontro Nacional da Anpur, 14, Rio de Janeiro. Disponível em: <http://www.anpur.org.br/site/anais/ena14/ ARQUIVOS/GT1-1-784-20110111235517.pdf>. Acesso em: 03 ago. 2011.

FAS - Fundação de Ação Social. (2010) Prefeitura e Cohab pavimentam ruas do Bolsão Audi/União. Publicado em 09 jun. 2010. Disponível em: < http:// www. fas. curitiba.pr. gov.br/noticia.aspx?idf=459>. Acesso em: 09 set. 2011.

GIL, A.C. (1996) Como elaborar projetos de pesquisa. São Paulo: Atlas.

LARCHER, J.W.M. (2005) Diretrizes visando a melhoria de projetos e soluções construtivas na expansão de habitações de interesse social. Dissertação (Mestrado em Construção Civil) - Setor de Tecnologia da Universidade Federal do Paraná, Curitiba. Disponível em: <http://www. prppg.ufpr.br/ppgcc/sites/www.prppg.ufpr.br.ppgcc/files/dissertacoes/ d0068.pdf > . Acesso em: 02 ago. 2013.

MILANO, J.Z. \& BONADIO, M.G. (2012) Curitiba: onde está a habitação de interesse social? In: Seminário Internacional Urbicentros, 3, Anais... Salvador, Disponível em: <http://www.ppgau.ufba.br/urbicentros/2012/ ST240.pdf > . Acesso em: 02 ago. 2013.

MINISTÉRIO DAS CIDADES. (2011) Sistema Nacional de Habitação de Interesse Social. Brasília. Disponível em: <http://www.cidades.gov. br/>. Acesso em: 28 set. 2011.

MINISTÉRIO DAS CIDADES; Secretaria Nacional de Habitação; Aliança de Cidades; Banco Mundial. (2011) Trabalho Social e Intervenções Habitacionais - Reflexões e aprendizados sobre o Seminário Internacional. Brasília: Ministério das Cidades. Disponível em: <http:// www.cidades.gov.br/images/stories/ArquivosSNH_ /ArquivosPDF/ Publicacoes/Cidades_Web_Final_02.pdf>. Acesso em: 28 mar. 2012.

ORNSTEIN, S. (1992) Avaliação pós-ocupação (APO) do ambiente construído. Marcelo Roméro (colaborador). São Paulo: Studio Nobel: Editora da Universidade de São Paulo, 223 p.

ROMÉRO, M.A. \& ORNSTEIN, S. (2003) Avaliação pós Ocupação: métodos e técnicas aplicados à habitação social. Coleção Habitare. Porto Alegre: ANTAC. 294 p.

ROMÉRO, M.A. \& VIANA, N.S. (2002) Procedimentos metodológicos para aplicação de avaliação de pós-ocupação em conjuntos habitacionais de baixa renda: do desenho urbano à unidade habitacional. In: ABIKO, A.K. \& ORNSTEIN, S.W. (Ed.) Inserção urbana e Avaliação pósocupação (APO) da Habitação de Interesses Social. Coletânea Habitare. São Paulo: FINEP, 2002. Cap. 8. P. 211-241. 